\title{
New-Generation Fetal Dose Estimates for Radiopharmaceuticals
}

\author{
Michael G. Stabin \\ RAdiation Dose Assessment Resource (RADAR) Committee of the Society of Nuclear Medicine and Molecular Imaging, Reston, \\ Virginia, and Department of Radiology and Radiological Sciences, Vanderbilt University, Nashville, Tennessee
}

Radiopharmaceutical dose estimates to the fetus have been based for many years on the reported placental crossover data and dose estimates of Russell et al. $(1,2)$, which used pregnant female phantoms developed by Oak Ridge National Laboratory (Fig. 1) (3). New fetal dose estimates have now been generated using the new RAdiation Dose Assessment Resource (RADAR) International Commission on Radiological Protection (ICRP) 89 reference female pregnant and nonpregnant models (Fig. 2) (4), as implemented in the OLINDA/ EXM 2.0 software (5). Table 1 summarizes the differences in the masses of the fetus, placenta, and uterus between the two sets of models.

Most maternal and fetal time-activity integrals were taken from Russell et al. (2), to maintain consistency with the previous estimates. Although biokinetic models may have changed somewhat, the previous values were retained. One exception is that dose estimates for ${ }^{18} \mathrm{~F}$-FDG were taken from Zanotti-Fregonara and Stabin (6), as this publication provided a significant update to the older dose estimates, including placental crossover. Other radiopharmaceuticals, not considered by Russell et al., were added; references are given in Supplemental Table 1 (supplemental materials are available at http:// jnm.snmjournals.org).

When the literature provides no information on placental crossover, only maternal contributions to fetal dose can be considered. If there is placental crossover, this may underestimate fetal doses, but there is no reliable way to arbitrarily assign placental crossover in the absence of any scientific data. As with the adult/pediatric RADAR radiopharmaceutical dose compendium (5), this article will be maintained in electronic format, allowing for revisions and additions, as needed.

Doses are provided for "early pregnancy" (dose to the nongravid uterus in the RADAR reference adult female model) and to the fetus at 3,6, and 9 mo of gestation. Uncertainties in using these estimates for a specific subject are considerable, both in the physiology of the radiopharmaceutical kinetics and in the assumed geometry of the maternal and fetal organs. Dose estimates that bracket a given reallife exposure (e.g., for a case at 4 mo of gestation, the 3- and 6-mo values can be applied) should not use sophisticated interpolation methods. Rather, one should look at the dose estimate on either side, take the higher of the two, and round to 1 significant figure to give an estimate to a real patient. For example, if a pregnant woman at 4 mo of gestation is administered $370 \mathrm{MBq}$ of ${ }^{18} \mathrm{~F}-\mathrm{FDG}$, the estimated fetal dose from Supplemental Table 1 is $7.0 \mathrm{mGy}$ at $3 \mathrm{mo}$ and $5.2 \mathrm{mGy}$ at $6 \mathrm{mo}$; an estimate of $5-7 \mathrm{mGy}$ is reasonable and conservative.

Received Oct. 24, 2017; revision accepted Nov. 21, 2017.

For correspondence or reprints contact: Michael Stabin, Vanderbilt University, 116121 st Ave. S., Nashville, TN 37232.

E-mail: michael.g.stabin@vanderbilt.edu

Published online Dec. 21, 2017.

COPYRIGHT (c) 2018 by the Society of Nuclear Medicine and Molecular Imaging. DOI: 10.2967/jnumed.117.204214

\section{DISCLOSURE}

No potential conflict of interest relevant to this article was reported.
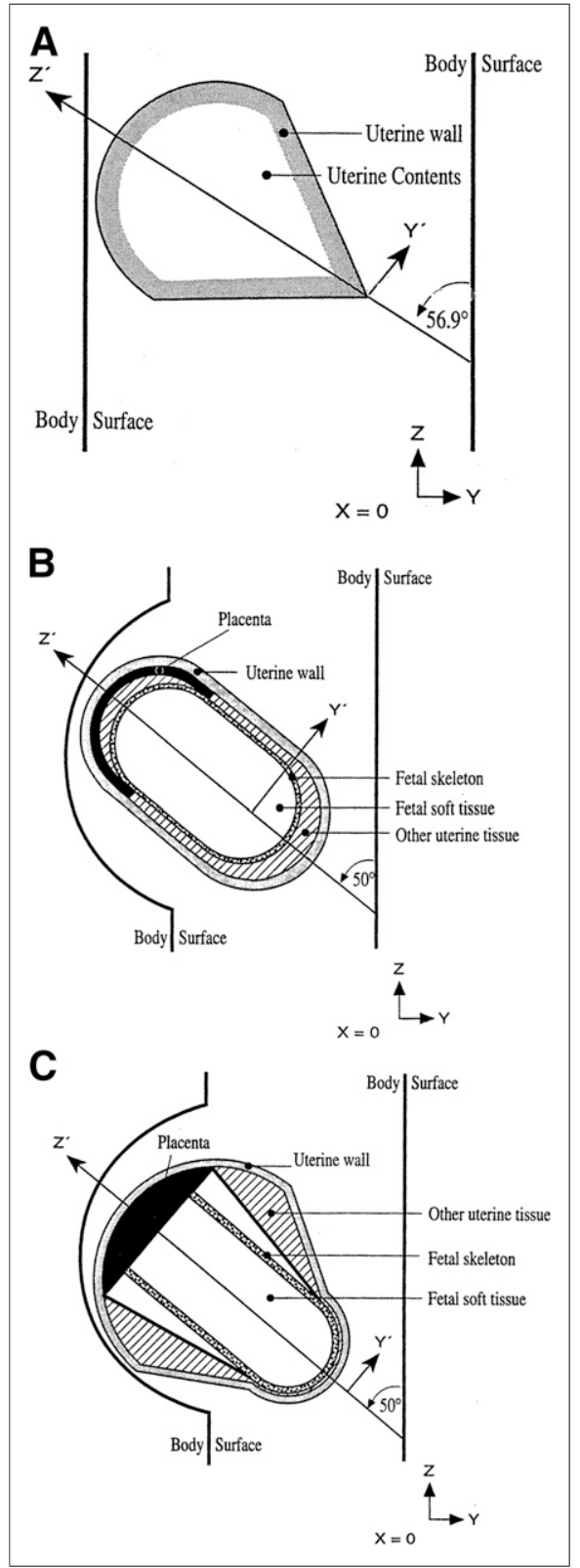

FIGURE 1. Oak Ridge National Laboratory pregnant female models for 3 $\mathrm{mo}(\mathrm{A}), 6 \mathrm{mo}(\mathrm{B})$, and $9 \mathrm{mo}$ (C) of gestation. (Reprinted with permission of (3).) 
TABLE 1

Masses of Fetus, Placenta, and Uterus in RADAR (4) and Oak Ridge National Laboratory (3) Pregnant Female Phantoms

\begin{tabular}{|c|c|c|c|c|c|c|}
\hline \multirow[b]{2}{*}{ Source organ } & \multicolumn{3}{|c|}{ RADAR (g) } & \multicolumn{3}{|c|}{$\begin{array}{l}\text { Oak Ridge National } \\
\text { Laboratory }(\mathrm{g})\end{array}$} \\
\hline & $3 \mathrm{mo}$ & $6 \mathrm{mo}$ & $9 \mathrm{mo}$ & $3 \mathrm{mo}$ & $6 \mathrm{mo}$ & $9 \mathrm{mo}$ \\
\hline Fetus & 85 & 1,115 & 3,495 & 485 & 1,640 & 2,960 \\
\hline Placenta & 48 & 319 & 650 & 0 & 310 & 466 \\
\hline Uterus & 270 & 550 & 1,047 & 374 & 834 & 1,095 \\
\hline
\end{tabular}

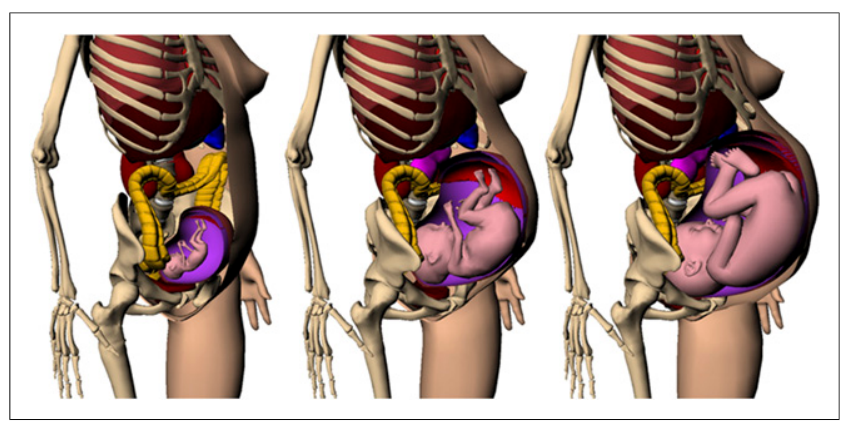

FIGURE 2. Rensselaer Polytechnic Institute pregnant female models for $3 \mathrm{mo}$ (left), $6 \mathrm{mo}$ (middle), and $9 \mathrm{mo}$ (right) of gestation (7).

\section{REFERENCES}

1. Russell JR, Stabin M, Sparks R. Placental transfer of radiopharmaceuticals and dosimetry in pregnancy. Health Phys. 1997;73:747-755.

2. Russell JR, Stabin MG, Sparks RB, Watson EE. Radiation absorbed dose to the embryo/fetus from radiopharmaceuticals. Health Phys. 1997;73:756-769.

3. Stabin MG, Watson EE, Cristy M, et al. Mathematical Models and Specific Absorbed Fractions of Photon Energy in the Nonpregnant Adult Female and at the End of Each Trimester of Pregnancy. Oak Ridge, TN: Oak Ridge National Laboratory; 1995. Report ORNL/TM-12907.

4. Stabin MG, Xu XG, Emmons MA, Segars WP, Shi C, Fernald MJ. RADAR reference adult, pediatric, and pregnant female phantom series for internal and external dosimetry. J Nucl Med. 2012;53:1807-1813.

5. Stabin MG, Siegel JA. RADAR dose estimate report: a compendium of radiopharmaceutical dose estimates based on OLINDA/EXM version 2.0. J Nucl Med. 2018;59:154-160.

6. Zanotti-Fregonara P, Stabin MG. New fetal dose estimates for ${ }^{18} \mathrm{~F}-\mathrm{FDG}$ based on human data. J Nucl Med. 2017;58:1865-1866.

7. Xu XG, Taranenko V, Zhang J, Shi C. A boundary-representation method for designing whole-body radiation dosimetry models: pregnant females representing three gestational periods RPI-P3, -P6 and -P9. Phys. Med. Biol. 2007;52:7023-7044. 